\title{
COEXISTÊNCIA: A EXPOSIÇÃO DE ARTE COMO LUGAR DE PESQUISA, ENSINO E EXTENSÃO
}

\author{
Manoela dos Anjos Afonso Rodrigues, Vera Regina Barbuy \\ Wilhelm, Eliane Maria Chaud
}

\begin{abstract}
Resumo: Neste artigo, discorremos sobre a experiência pedagógica de reunir as disciplinas Trabalho de Conclusão de Curso 2, Laboratório de Produção Artística $4 \mathrm{e}$ Expografia e Montagem com o objetivo de realizar uma exposição das pesquisas em arte conduzidas pelos estudantes do quarto e último ano do curso Artes Visuais Bacharelado, da Faculdade de Artes Visuais da Universidade Federal de Goiás. Esta exposição é uma atividade prevista no Projeto Pedagógico do curso desde o ano 2012. Porém, foi em 2017 que pudemos realizar a primeira mostra do gênero na Galeria da FAV como uma ação de extensão. No presente trabalho, concluímos que ao traçarmos um projeto interdisciplinar para conectar a sala de aula a uma experiência expositiva na galeria, criamos um importante espaço de convergência entre ensino, pesquisa, extensão e formação profissional que beneficia tanto os nossos estudantes quanto a comunidade externa à UFG.
\end{abstract}

Palavras-chave: Artes Visuais. Exposição de Arte. Ensino de Arte. Pesquisa em Arte. Extensão.

\section{COEXISTENCE: THE ART EXHIBITION AS PLACE FOR RESEARCH, TEACHING AND EXTENSION}

\begin{abstract}
In this article, we present the pedagogical experience of bringing together three subjects (Trabalho de Conclusão de Curso 2, Laboratório de Produção Artística $4 \mathrm{e}$ Expografia e Montagem) aiming to carry out an exhibition for showing the art research conducted by the final-year students of the Visual Arts - Bachelor's degree, at the Visual Arts College of the Federal University of Goiás. Since 2012, this exhibition is required in the Pedagogical Project of the course. However, only in 2017 we managed to hold the first exhibition of this kind at the Galeria da FAV as an extension event. In this paper, we claim that by building an interdisciplinary project for connecting the classroom to
\end{abstract}


the students' art exhibition at the galley we have created an important space for the convergence of teaching, research, extension and professional training, stimulating not only our students but also the community outside UFG.

Keywords: Visual Arts. Art Exhibition. Art Teaching. Art Research. Extension.

COEXISTENCIA: LA EXPOSICIÓN DE ARTE COMO LUGAR DE INVESTIGACIÓN, ENSEÑANZA Y EXTENSIÓN

RESUMEN: En este artículo, presentamos la experiencia pedagógica de reunir tres disciplinas (Trabalho de Conclusão de Curso 2, Laboratório de Produção Artística $4 \mathrm{e}$ Expografia e Montagem) con el objetivo de llevar a cabo una exposición para mostrar la investigación artística realizada por los estudiantes de último año del curso Artes Visuales - Bacharelado, da Faculdade de Artes Visuales de la Universidad Federal de Goiás. Desde 2012, la exposición es una actividad prevista en el Proyecto Pedagógico del curso. Sin embargo, fue en 2017 que pudimos realizar la primera muestra de este tipo en la Galería de la FAV como una acción de extensión. En el presente trabajo, concluimos que al trazar un proyecto interdisciplinario para conectar el aula a una experiencia expositiva en la galería, creamos un importante espacio de convergencia entre enseñanza, investigación, extensión y formación profesional que beneficia tanto a nuestros estudiantes como a la comunidad externa a la UFG.

Palabras clave: Artes Visuales. Exposición de Arte. Enseñanza de Arte. Investigación en Arte. Extensión.

\section{INTRODUÇÃO}

Planejar e realizar uma exposição que reúne as pesquisas em arte de estudantes de artes visuais significa mais do que apenas dispor imagens e objetos num espaço expositivo. A mostra em si constitui uma importante narrativa que explicita ideias, conteúdos, processos e resultados provenientes do esforço conjunto de alunas e alunos, professoras, professores e técnicos administrativos para criar um espaço generoso de visibilidade e acesso aos fazeres e saberes construídos ao longo de um curso superior em artes visuais.

Neste artigo, discorremos sobre a experiência pedagógica de reunir as disciplinas Trabalho de Conclusão de Curso 2 (TCC2), Laboratório de Produção Artística 4 e Expografia e Montagem com o objetivo de realizar uma exposição das pesquisas em arte conduzidas pelos estudantes do quarto e último ano 
do curso Artes Visuais - Bacharelado (AVB), da Faculdade de Artes Visuais (FAV) da Universidade Federal de Goiás (UFG). Esta exposição é uma atividade prevista no Projeto Pedagógico do curso desde o ano 2012. Porém, foi em 2017 que pudemos realizar a primeira mostra do gênero na Galeria da FAV como ação de extensão que reuniu uma professora do curso de Museologia e duas professoras do curso AVB. A exposição foi cadastrada como evento de extensão, pois acreditamos que esta é uma atividade que traz benefícios não só para os estudantes e para a comunidade acadêmica, mas também para a comunidade externa à UFG, já que a exposição se configura como espaço dialógico de compartilhamento de fazeres e saberes por meio do contato direto com a arte e seus processos.

Além disso, constatamos que a realização dessa exposição de estudantes na Galeria da FAV se constitui em si como uma conquista, já que a política artístico-cultural desta galeria esteve concentrada, durante muitos anos, na mostra e circulação de trabalhos de artistas com trajetórias consagradas. Com esta abertura, no ano 2017, a Galeria da FAV passa a participar de forma ainda mais significativa da formação de nossos estudantes, pois agora os acolhe e os convida a praticar o espaço por meio das pesquisas em arte que vêm realizando durante o curso AVB. Neste sentido, compreendemos que a exposição de estudantes realizada na Galeria da FAV em 2017 pode ser considerada uma semente que já germinou e se expande, pois a mostra de 2018 já se encontra em planejamento. Vale ressaltar também que se instaurou, a partir da exposição de 2017, um importante rito de passagem para discentes do curso AVB em fase de conclusão do curso.

Este texto está dividido em quatro partes. Na primeira seção, apresentamos uma reflexão sobre os processos da pesquisa em arte no curso AVB. Na segunda parte, discorremos sobre a dinâmica da disciplina Laboratório de Produção Artística 4. Em seguida, na terceira parte, demonstramos como a disciplina Expografia e Montagem foi conduzida e se transformou num lugar de articulação da exposição que aqui é objeto deste artigo. Por fim, na quarta e última parte, tecemos nossas considerações finais.

\section{Pesquisa em arte}

A pesquisa em arte está presente no currículo do curso AVB de diversas formas e em vários níveis. Porém, ela é oficializada como conteúdo acadêmico 
pelas disciplinas Introdução ao Trabalho de Investigação, Pesquisa em Artes Visuais, Trabalho de Conclusão de Curso 1 (TCC1) e Trabalho de Conclusão de Curso 2 (TCC2). Neste texto, compreendemos e nos referimos à "pesquisa em arte" como um "trabalho de pesquisa em criação artística, empreendido por artistas que objetivam atingir como produto final a obra de arte" (ZAMBONI, 2012, p. 6). Portanto, consideramos principalmente as pesquisas de cunho teórico-prático, embora reconheçamos que para realizarmos uma "pesquisa em arte" com certa profundidade é necessário realizar, em certa medida, também uma "pesquisa sobre arte" (REY, 1996, p. 82), ou seja, uma pesquisa de cunho teórico no campo da história da arte e/ou da teoria da arte e da cultura.

É importante ressaltar que o "produto final" de uma pesquisa em arte não necessariamente se apresenta como um produto finalizado, acabado e/ou estável. Lidamos com a ideia de produtos em processo, pois compreendemos que os próprios processos artísticos engendrados durante a pesquisa acadêmica podem ser considerados resultados parciais relevantes para o campo das artes visuais e, portanto, dignos de reflexão, análise e comunicação. Além disso, é importante frisar que os resultados de uma pesquisa em arte nem sempre se acomodam tão facilmente no próprio campo da arte, devido principalmente ao caráter inter-, trans-, multi- ou pós- disciplinar de tais pesquisas.

Ao refletir sobre a "pósdisciplina" na pesquisa em arte, Sullivan afirma que "a prática posdisciplinar descreve o modo como a pesquisa em artes visuais ocupa um lugar dentro e além das fronteiras disciplinares existentes à medida que dimensões da teoria são exploradas e domínios de investigação adaptados" (SULLIVAN, 2010, P. 111, tradução nossa). Sendo assim, a pesquisa em arte pode engendrar processos de investigação acadêmica e artística que se articulam por meio de operações poéticas que nem sempre lançam suas principais perguntas diretamente para o campo da arte. As perguntas elaboradas no cerne de uma pesquisa em arte podem, portanto, conduzir os estudantes por uma caminhada entre disciplinas, levando-os a produzir não só um conhecimento sobre o campo da arte, mas também sobre outros campos por meio da prática artística que se configura ela própria como uma metodologia de pesquisa. Sullivan ainda afirma que "muitos artistas hoje em dia não restringem a sua prática a uma forma singular de explorar um estilo pessoal ou um tema particular recorrente, mas preferem usar suas habilidades em métodos e multimídia para endereçar questões mais amplas de relevância humana e cultural” (SULLIVAN, 2010, p. 97, tradução nossa). 
No quarto e último ano do curso AVB, as disciplinas TCC1 e TCC2 formam o ponto de confluência dos estudos teóricos e processos artísticos desenvolvidos pelos estudantes ao longo dos três anos anteriores. É no último ano, portanto, que um importante espaço de articulação de pensamento, argumentação teórica, pesquisa acadêmica e prática artística é criado no âmbito dessas disciplinas. Inicialmente, na disciplina TCC1, espera-se que os estudantes coloquem em prática o projeto de pesquisa delineado previamente, no sexto período, durante a disciplina Pesquisa em Artes Visuais. Então, a partir dos esforços de concretização desse projeto na disciplina TCC1, diversos caminhos para a pesquisa em arte se abrem, de modo que os estudantes podem buscar um aperfeiçoamento da prática da pesquisa acadêmica contando com o auxílio de professoras e professores orientadores. Ao final da disciplina TCC1, alunas e alunos são avaliados durante as pré-bancas de TCC, momento público em que os estudantes devem comunicar de forma clara e objetiva os processos e resultados parciais obtidos em sua pesquisa até então.

No semestre seguinte, durante a disciplina TCC2, os estudantes são orientados a finalizar os processos de investigação por meio da conclusão tanto do trabalho escrito quanto dos trabalhos artísticos. Este é o momento em que a exposição de arte se faz extremamente necessária, pois é através dela que a pesquisa em arte ganha visibilidade e pode, então, gerar debates importantes e elementos concretos para a avaliação tanto dos alunos quanto do trabalho de formação que estamos realizando no curso AVB. Além disso, a exposição oferece um espaço de diálogo entre estudantes, professores, familiares e demais membros da comunidade sobre a variedade e qualidade dos conhecimentos gerados pelos processos artísticos criados pelos estudantes.

O momento da exposição é tão relevante para a formação do Bacharel em Artes Visuais na FAV/UFG que durante o processo de reformulação do Projeto Pedagógico do Curso (PPC), conduzido nos anos 2011 e 2012, a "realização de exposição contemplando o trabalho desenvolvido" pelos alunos passou a fazer parte da ementa da disciplina TCC2 (AFONSO, JORGE e SAMPAIO, 2012, p. 32). Compreende-se, portanto, que a exposição é um elemento indispensável ao exercício e à existência da/o artista em formação e, portanto, não poderia deixar de estar presente de forma mais contundente nos processos de ensino-aprendizagem vivenciados pelos nossos alunos. Decidimos, assim, sinalizar a relevância da exposição no PPC do curso AVB criando, também, a disciplina Expografia e Montagem, que prevê o "estudo dos espaços expositivos: legislação, 
montagem, circulação, sinalização, iluminação e conservação. Desenvolvimento de propostas curatoriais e expográficas a partir dos trabalhos desenvolvidos nas disciplinas TCC 1 e 2" (AFONSO, JORGE e SAMPAIO, 2012, p. 31).

Tais esforços locais estão em sintonia com os esforços nacionais que vêm sendo empreendidos pelo Fórum Nacional de Coordenadores de Cursos de Graduação em Artes Visuais ${ }^{1}$, criado em 2012, em Niterói, com o objetivo de destacar a importância da existência de espaços expositivos nos cursos de graduação em artes no Brasil. Em 2017, o coordenador do fórum, professor Milton Sogabe (2014), redigiu uma carta endereçada aos pró-reitores de graduação das universidades brasileiras. Neste documento, ele reforça a relevância do espaço expositivo para os cursos de artes, pois:

\begin{abstract}
Nesses espaços acontece uma das principais atividades que é a divulgação da produção artística do curso, além da oportunidade de apresentação de produções de outros artistas externos à universidade, quando os alunos têm a oportunidade de ter acesso às obras e contato com artistas para discussão. Nesse processo, os alunos assumem um compromisso maior com sua produção e amadurecem profissionalmente. Nesses espaços são desenvolvidas atividades de ensino relacionadas à curadoria, crítica de arte, montagem de mostras, desenvolvimento de projetos gráficos, trabalho de mediação do público com as obras, visitas guiadas para escolas do ensino fundamental e médio, workshops e defesas de trabalho de conclusão de curso com exposição. Várias disciplinas relacionam-se com estas atividades e usam esses espaços como "sala de aula", sejam da área teórica, da área de linguagens poéticas, ou da área de arte-educação, seja na graduação ou pós-graduação (SOGABE, 2014, p. 1).
\end{abstract}

Além disso, o Fórum Nacional de Coordenadores de Cursos de Graduação em Artes Visuais destaca a relevância da exposição para a extensão, uma vez que "uma Galeria ou Museu de Arte da Universidade é um espaço onde pode acontecer o diálogo da universidade com a comunidade" (SOGABE, 2014, p. 1).

Pensando nestas questões, no início do segundo semestre de 2017, a coordenação do curso AVB da FAV/UFG buscou articular uma ação interdisciplinar reunindo as professoras das disciplinas TCC2, Laboratório de Produção Artística 4 e Expografia e Montagem, com o objetivo encontrar pontos em comum entre tais disciplinas para, assim, colocar práticas pedagógicas em diálogo para que um trabalho conjunto pudesse ser realizado de forma a culminar

1 https://fcgartesvisuais.jimdo.com/ 
na concretização de uma exposição, na Galeria da FAV, das pesquisas em arte dos estudantes do quarto e último ano do curso. Este não foi um trabalho fácil, pois tivemos que aprender a relacionar nossas disciplinas em pleno movimento do segundo semestre de 2017. Porém, foi uma experiência enriquecedora e elucidativa, pois após tomarmos distância temporal e espacial do intento realizado, percebemos melhor a importância dos resultados obtidos e colhemos elementos para uma análise crítica de nossos propósitos, o que já tem nos ajudado a planejar as próximas exposições neste contexto.

Na próxima parte do texto, apresentamos a dinâmica desenvolvida na disciplina Laboratório de Produção Artística 4, como estratégia de aproximação das outras duas disciplinas e com foco na exposição a ser concretizada.

\section{LABORATÓRIO DE PRODUÇÃO ARTÍSTICA}

A pergunta "por onde começar uma prática artística?" é o ponto de partida das ações desenvolvidas no Laboratório de Produção Artística 1, disciplina ministrada para os estudantes do curso AVB no quinto período. Alunas e alunos são estimulados, nesse momento inicial, a refletir profundamente sobre os processos de articulação de fazeres e pensares no contexto de um projeto poético latente, individual ou coletivo. Na disciplina Laboratório de Produção Artística 4, ministrada para alunos do oitavo período, espera-se que este projeto inicial tenha se desdobrado e se aprofundado ao longo do curso.

$\mathrm{Na}$ experiência interdisciplinar aqui relatada, observou-se que ao convidarmos os alunos a pensarem a sua própria produção artística não mais apenas no espaço da sala de aula mas no espaço expositivo da Galeria da FAV, questões importantes sobre processos de criação e formação de artistas tornaram-se evidentes. Notou-se uma elevação da potência do fazer artístico quando os estudantes passaram a ter como meta apresentar o seu trabalho publicamente num espaço que faz parte do circuito da arte da cidade de Goiânia. Neste contato do trabalho artístico com a comunidade, por meio da exposição, muitas trocas acontecem e algumas delas são extremamente relevantes para a inserção profissional da/o jovem artista. A exposição impacta diretamente na forma como não apenas a audiência entra em contato com a produção de um/a artista, mas na forma como o próprio artista compreende seu trabalho e atua no campo da arte e da cultura. 
A disciplina Laboratório de Produção Artística 4 teve como objetivo estimular os estudantes no desenvolvimento e na compreensão dos seus próprios processos de criação, explorando possibilidades técnicas, materiais, instrumentais e conceituais. A partir da compreensão das questões que motivam suas pesquisas em arte e dos conceitos que permeiam os seus trabalhos, os estudantes foram finalizando suas propostas artísticas de acordo com o andamento das orientações dadas na disciplina TCC2.

As atividades foram orientadas a partir das questões tratadas no texto $A$ matéria artística, de Luigi Pareyson (1997). Neste texto, destaca-se a presença do elemento físico indispensável para a arte, elemento este que leva à compreensão da arte a partir da construção de um objeto que tem consistência física e que se conecta também a uma realidade sensível. A partir destas compreensões, alguns questionamentos foram feitos a cada indivíduo ou grupo de alunos, tais como: Qual a matéria utilizada para o seu trabalho artístico? Quais características físicas eles apresentam? O que lhe interessa nestas características? Quais são as questões artísticas que o inquieta e lhe faz querer investigar o assunto escolhido? O que é importante para você no trabalho? Qual o princípio do trabalho? Quais as intenções em desenvolver este trabalho artístico? Para Sonia Rangel (2009), estas são perguntas-passaporte que "levam a sondar os pensamentos da imagem e as imagens do pensamento em novas obras" (RANGEL, 2009, p. 127).

Ao criar e pensar sobre tais questões, incentivamos os alunos a buscarem uma compreensão daquilo que estava sendo imaginado e percebido no trabalho, de forma que conseguissem identificar o método com o qual realizavam sua pesquisa em arte. Ao incentivar os estudantes a compreender e a organizar sua própria sensibilidade, eles passaram a construir sua maneira específica de operacionalizar a matéria, a técnica e os conceitos.

Ao longo da disciplina, os estudantes apresentaram suas propostas artísticas em diferentes meios expressivos. Esta diversidade de propostas constitui-se como um grande desafio a ser encarado e superado por estudantes e professoras no âmbito da disciplina Expografia e Montagem, já que este foi o lugar criado para pensarmos mais diretamente sobre como dispor o trabalho desenvolvido pelos alunos em relação ao espaço expositivo da Galeria da FAV. Na seção seguinte, apresentamos as estratégias adotadas na organização física e narrativa da exposição, de forma que pudessem acomodar pesquisas artísticas tão diversas, tais como: a investigação sobre o cheio e o vazio no desenho; 
as relações entre os espaços bidimensional e tridimensional; as aproximações entre arte e matemática na escultura; a pintura e a desconstrução do corpo; a gravura e o espaço urbano; as relações entre o onírico e o poético; memória, álbum de família e fotografia; autorretratos e decolonialidade; relações entre cinema, quadrinhos e animação; a criação de um universo ficcional por meio da animação digital; as relações entre arte, jogo e tecnologia, para citar apenas alguns aspectos do vasto universo explorado pelo grupo de estudantes que participou da exposição realizada no contexto deste projeto interdisciplinar.

\section{EXPOGRAFIA E MONTAGEM}

A ação de extensão desenvolvida no segundo semestre de 2017 teve como objetivo geral a realização da exposição COEXISTÊNCIA, evento que teve como objetivos específicos: mostrar a produção artística proveniente dos processos de pesquisa em arte conduzidos pelos estudantes do curso AVB nas disciplinas TCC2, Laboratório de Produção Artística 4 e Expografia e Montagem; divulgar o resultado final, na Galeria da FAV, de um exercício prático de planejamento, expografia e montagem de uma exposição desenvolvido por estes alunos no referido semestre e com base em suas pesquisas artísticas; concretizar o trabalho de pesquisa, concepção e execução do processo de comunicação do evento, envolvendo a comunidade local.

A disciplina Expografia e Montagem forneceu o conhecimento básico necessário para o desenvolvimento deste evento de extensão como sendo um trabalho de comunicação e extroversão num dado espaço cultural. As atividades envolveram, a princípio, conceitos teóricos para embasar a prática da produção de uma exposição com a finalidade de divulgar as obras produzidas pelos alunos num contexto de pesquisa acadêmica e, além disso, possibilitar o estreitamento de laços entre curadoria e produção técnica de uma exposição. Tais atividades podem, eventualmente, vir a se tornar uma prática a ser desenvolvida por alguns dos discentes em sua futura vida profissional.

Apesar do caráter interdisciplinar da exposição e da complexidade que as diversas áreas técnicas exigiram, a exposição executada na disciplina se configurou como um exercício prático a ser desenvolvido pelos próprios discentes, que se organizaram em diferentes grupos com atividades específicas e relativas às diferentes fases do processo de elaboração da exposição. Os alunos assumiram, neste contexto didático, a elaboração da exposição e vivenciaram 
não só as funções e as necessidades de cada profissional que deve estar envolvido no processo (tais como museólogos, conservadores, arquitetos, light designers, programadores visuais etc.), mas também as dificuldades inerentes a cada fase e atividade. Além disso, reconheceram a importância do trabalho conjunto e interdisciplinar. Na etapa inicial da disciplina, foram introduzidos vários conceitos sobre espaços expositivos e sobre o processo de produção de uma exposição. Na segunda etapa, foi realizado um trabalho mais prático onde cada grupo, já estruturado, realizou as suas respectivas atividades, que frequentemente eram apresentadas à turma para a tomada de decisão conjunta. A exposição, portanto, é fruto de um trabalho coletivo desenvolvido pelos discentes da FAV e coordenado por docentes (Figura 1).

FIGURA 1. Grupo de estudantes durante a montagem da exposição COEXISTÊNCIA na Galeria da FAV, novembro de 2017.

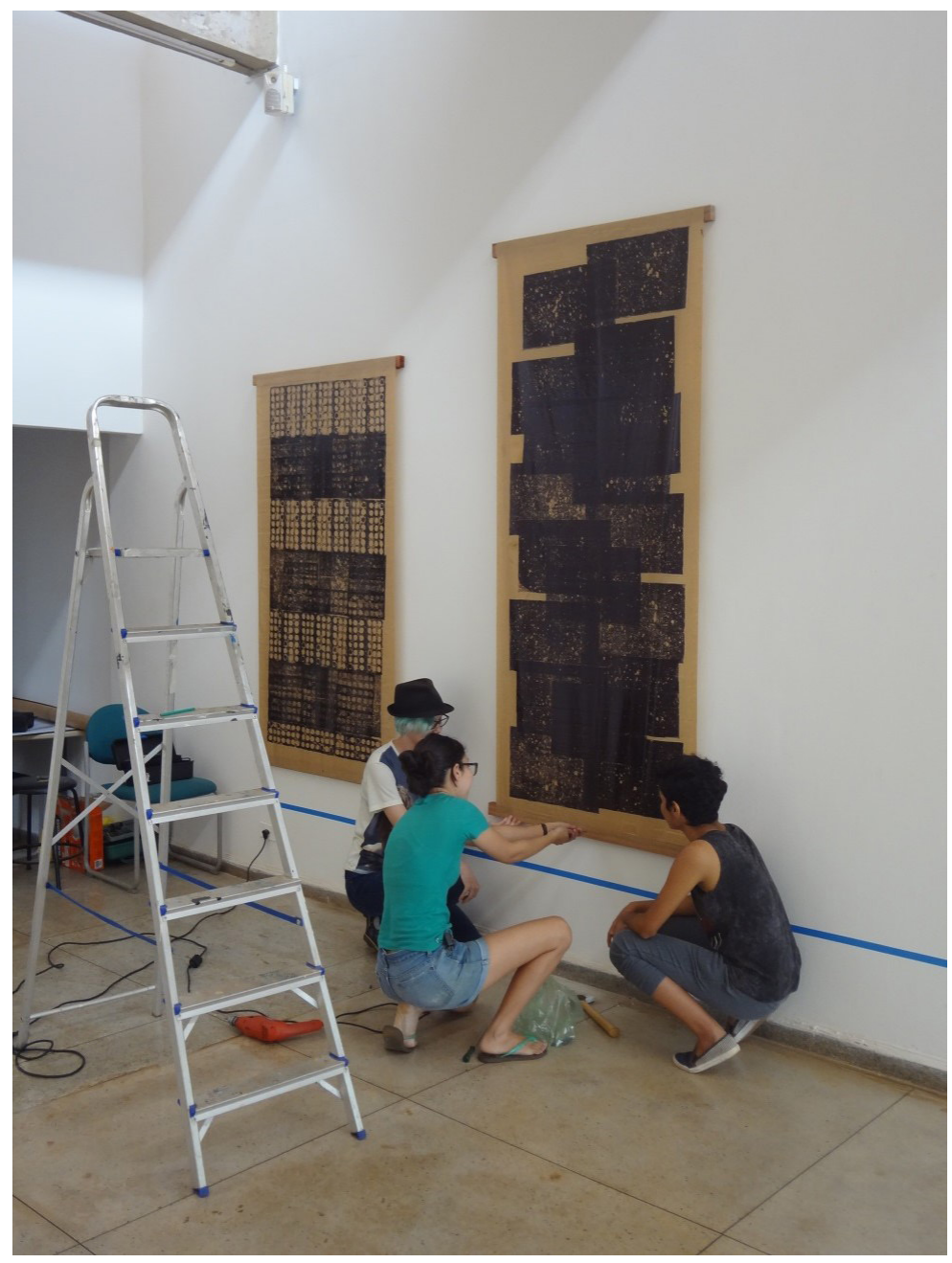

FONTE: ARQUIVO PESSOAL. 
O nome da exposição, COEXISTENNCIA, foi escolhido entre diversas sugestões feitas pelos alunos. O texto da exposição (Figura 2) foi elaborado por uma aluna cujo trabalho final, de natureza teórica, não seria apresentado na exposição. A montagem da exposição foi iniciada no dia 20 de novembro de 2017 e finalizada no dia seguinte. A exposição foi inaugurada no dia 22 de novembro de 2017, com duração até 08 de dezembro do mesmo ano (Figuras 3 e 4).

FIGURA 2. Texto de apresentação da exposição COEXISTÊNCIA na Galeria da FAV, novembro de 2017.

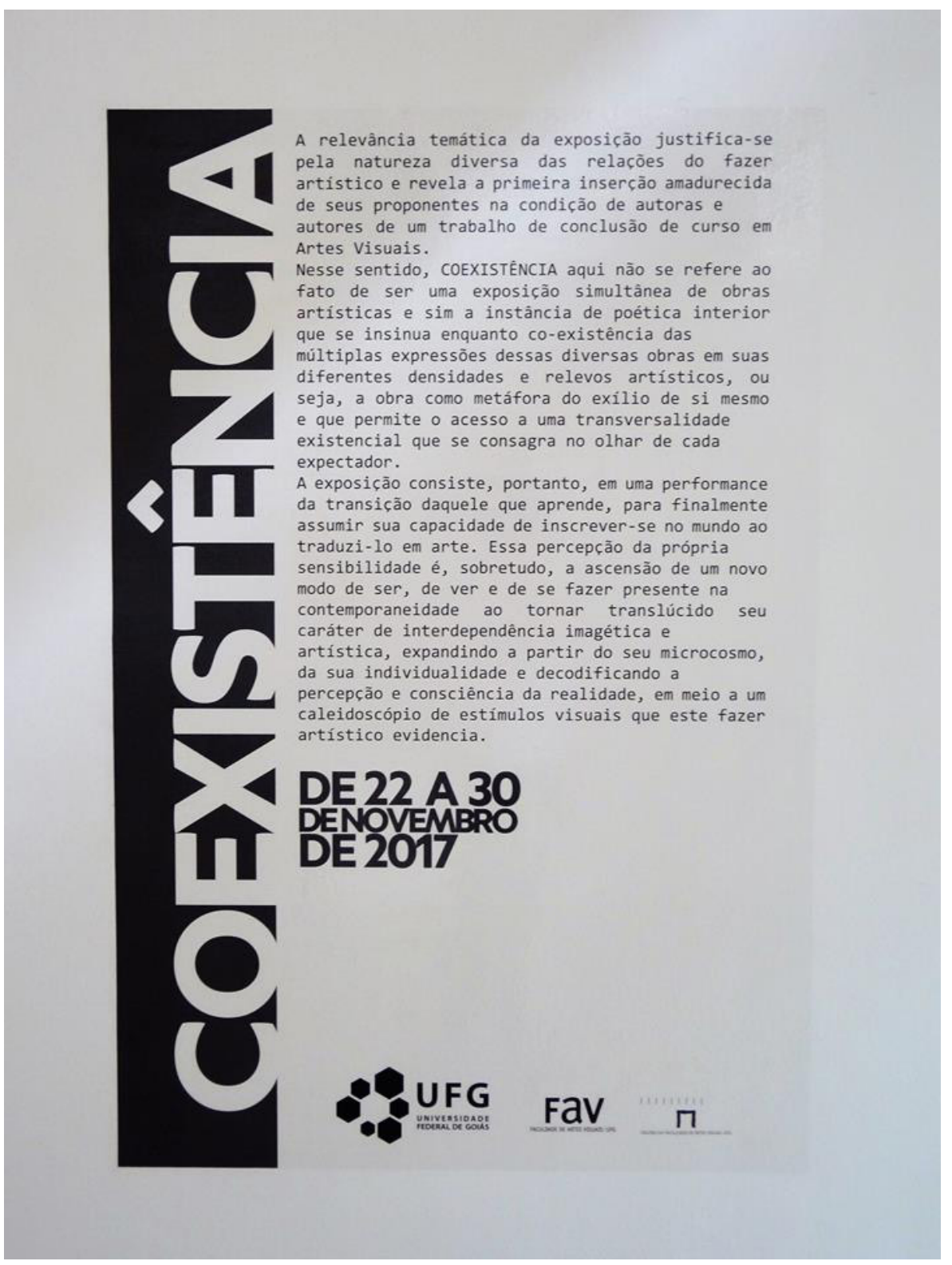

FONTE: ARQUIVO PESSOAL. 
FicuRA 3. Exposição COEXISTÊNCIA, Galeria da FAV, novembro de 2017.

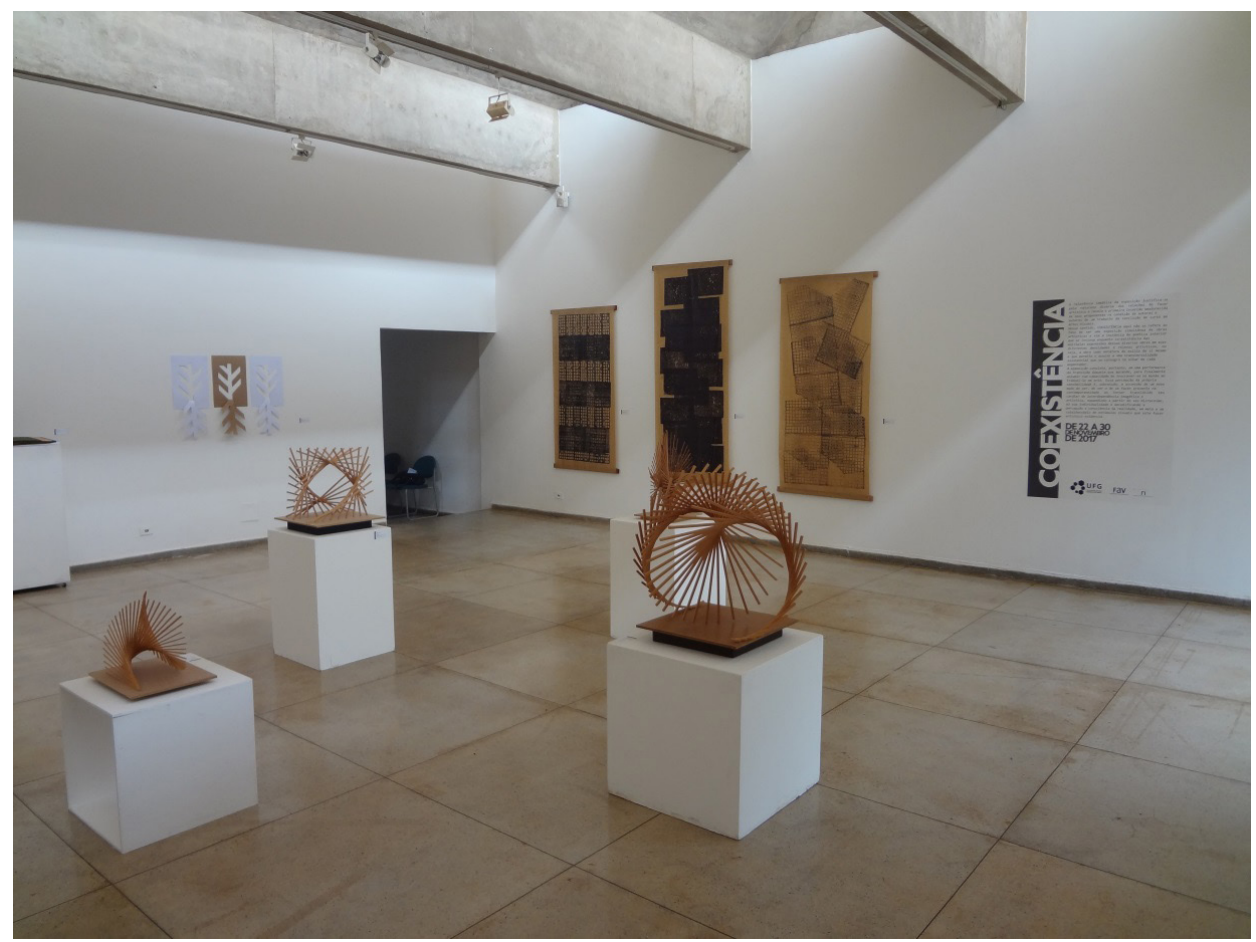

FONTE: ARQUIVO PESSOAL.

Ficura 4. Abertura da exposição COEXISTÊNCIA, Galeria da FAV, 22 de novembro de 2017.

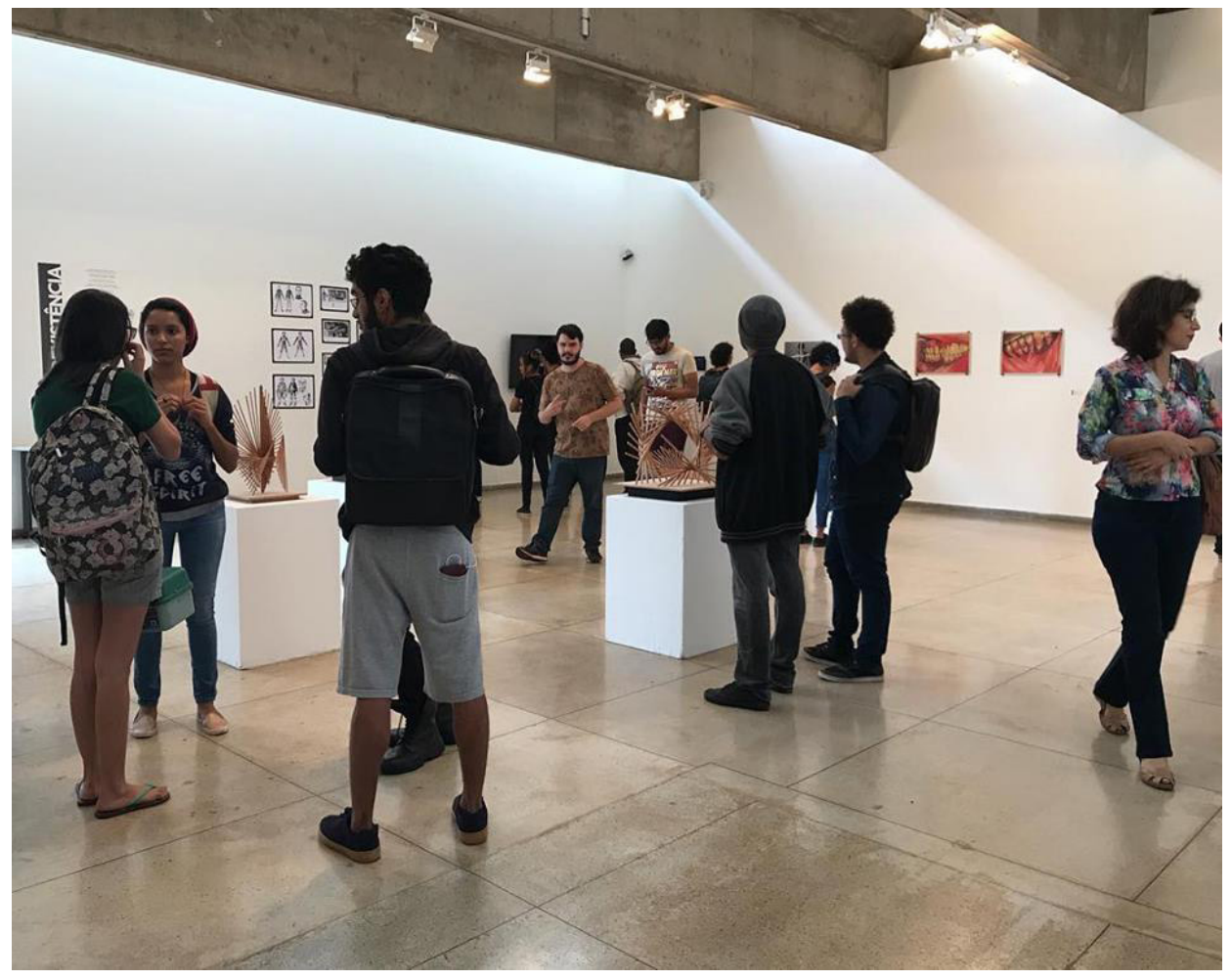

FONTE: ARQUIVO PESSOAL. 
A divisão dos grupos seguiu alguns conceitos definidos por CURY (2005) ao determinar as atividades e função das etapas e dos grupos de trabalho no processo geral da exposição. Porém, foi realizada de forma mais simplificada, já que não havia envolvimento de profissionais externos para cada área e o tempo de duração da exposição não permitia efetivar algumas etapas. Os grupos foram divididos em: planejamento; elaboração técnica; design/comunicação; montagem e desmontagem da exposição.

O grupo de Planejamento distribuiu tarefas, coordenou e auxiliou na organização geral das necessidades da exposição, dando suporte e realizando a comunicação entre grupos, além de elaborar uma planilha contendo o cronograma de trabalho, levantamento e diagnóstico de materiais, em conjunto com o grupo da Elaboração Técnica. O grupo da Elaboração Técnica executou o levantamento dos recursos materiais (como mobiliário, painéis, material de pintura etc.) necessários à organização do layout do espaço expositivo da Galeria da FAV. Foi executado, também, um levantamento das necessidades de cada discente para a correta exposição de suas obras. A partir de uma planta elaborada por esta equipe em escala 1:20, foi possível visualizar e articular a distribuição das obras no espaço disponível. O processo de montagem da exposição foi realizado pela equipe Montagem/Desmontagem, em conjunto com a equipe Elaboração Técnica, já que alguns discentes tinham interesse em participar de ambas as etapas e as fases do processo e atividades dos grupos estavam de certa forma interligadas. O grupo Design/Comunicação elaborou o material visual e de divulgação da exposição. A partir da escolha do nome da exposição, feita em conjunto com os discentes, foi desenvolvido o material gráfico com design e cores que atribuíram uma identidade visual à mostra. Depois, o texto da exposição (Figura 2), a ficha técnica, bem como as etiquetas das obras colocadas na Galeria da FAV foram impressas por uma gráfica e aplicadas no local pelos alunos.

Uma vez preparado o local, iniciou-se o recebimento das obras na galeria da FAV, cujo controle foi feito por uma planilha criada para registro da entrada e saída das obras. A maioria das obras era bidimensional, além de alguns trabalhos de mídia digital e outros poucos tridimensionais. Os materiais que foram usados para auxiliar na montagem e fixação das obras eram, em grande parte, aqueles já existentes na galeria. Alguns outros materiais foram fornecidos por alguns dos discentes. O custo foi arcado pelos alunos e se restringiu à impressão do texto, da ficha técnica e das etiquetas pela gráfica. 
Como produto desta ação, foi criado também um catálogo digital ${ }^{2}$ elaborado pelos estudantes, contendo um texto de apresentação produzido pelas professoras das disciplinas TCC2, Laboratório de Produção Artística 4 e Expografia e Montagem, bem como o texto de apresentação da mostra (Figura 2) e imagens dos trabalhos artísticos apresentados pelos estudantes acompanhadas de textos sobre a pesquisa em arte desenvolvida por eles.

A divulgação da exposição foi feita por meio de envio de e-mails para o corpo docente da FAV e para a imprensa local em geral ${ }^{3}$ através do mailing da Galeria da FAV. Além disso, foi criado um evento no Facebook ${ }^{4}$ e feita uma distribuição de cartazes pelo Campus II da UFG, os quais foram afixados em lugares estratégicos. Com o empenho e dedicação dos discentes o resultado esperado foi alcançado apesar do pouco recurso disponível. A ação não só proporcionou a divulgação das pesquisas dos alunos, mas também promoveu a valorização da produção artística discente e, em alguns casos, foi possível estabelecer relações e parcerias profissionais futuras com o público externo e também da comunidade acadêmica, devido ao produto bem sucedido desta ação de extensão. Isso só enalteceu a importância de eventos desta natureza como atividade essencial e estimulante para unir a formação em artes visuais, a produção artística e a inserção da/o artista nos diversos segmentos do circuito das artes na cidade e além.

Os próprios estudantes que estavam expondo suas pesquisas se organizaram para recepcionar os visitantes durante o período em que a mostra esteve em cartaz, fator que favoreceu a troca de informações e conhecimentos oriundos das especificidades dos processos de investigação vivenciados por cada um deles. Na Figura 5, por exemplo, o estudante do curso AVB, Huggo Piantino, explica sua pesquisa intitulada NostalgicWave 95: reflexões sobre o jogo como processo artístico (Figura 6), desenvolvida em colaboração com outro estudante do curso AVB, Leonardo Lemes. No grupo presente nesta fotografia, figuram ainda o diretor da FAV/UFG e um jovem estudante do Ensino Médio acompanhado de sua mãe e irmã. Este estudante se dirigiu à FAV para conversar com os coordenadores dos cursos AVB e Design Gráfico a fim de decidir

2 https://expocoexistencia.wixsite.com/coexistencia

3 https://www.ufg.br/e/20259-fav-expoe-trabalhos-dos-formandos-no-curso-de-artes-visuais

4 https://www.facebook.com/events/366211217157048/ 
qual curso superior seria o melhor para o seu perfil. Ao visitar a exposição, o jovem teve a possibilidade de compreender o que estudamos e fazemos no curso AVB, bem como teve a oportunidade de conversar pessoalmente com estudantes em processo de finalização da graduação e na presença da pesquisa artística que realizam. Este encontro, de certa forma, representa os demais encontros que aconteceram na Galeria da FAV neste período. Por meio dele podemos notar a importância da exposição de arte como ação de formação, pesquisa e extensão.

FICURA 5. Estudante explicando sua pesquisa em arte para visitantes da exposição COEXISTÊNCIA, Galeria da FAV, novembro de 2017.

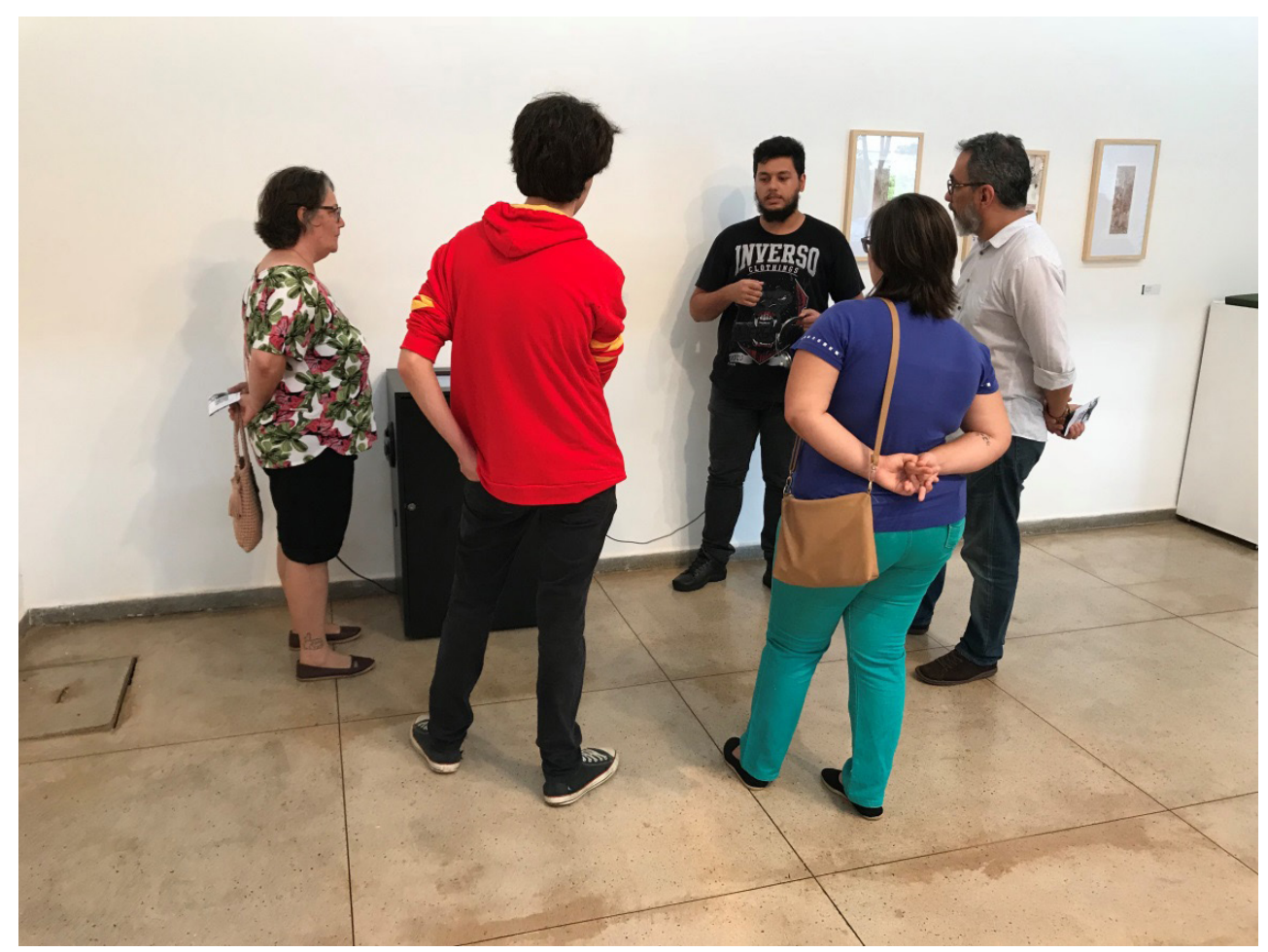

FONTE: ARQUIVO PESSOAL. 
Ficura 6. NostalgicWave 95: reflexões sobre o jogo como processo artístico. Trabalho artístico interativo criado no contexto da pesquisa em arte desenvolvida pelos estudantes Huggo Piantino e Leonardo Lemes.

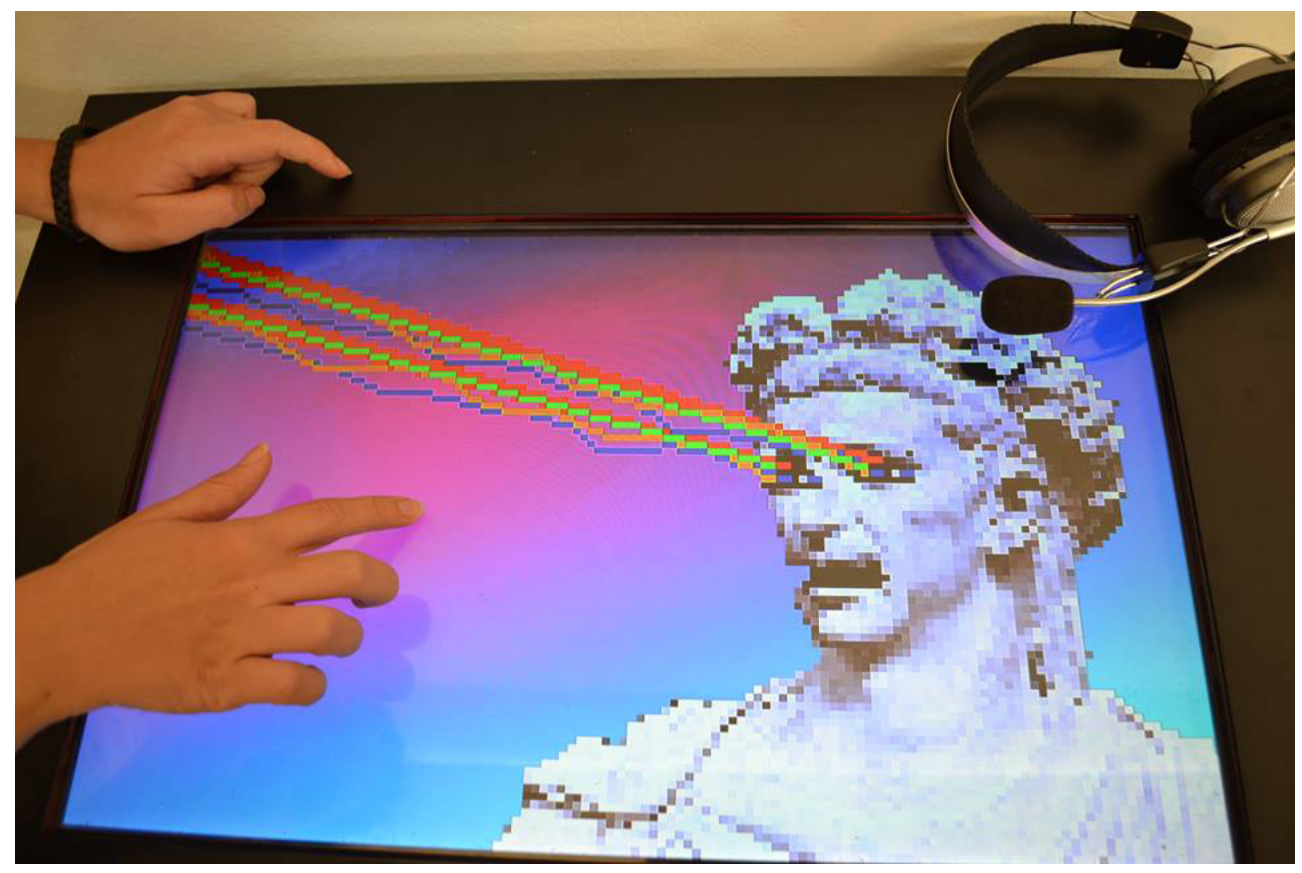

No último dia de aula da disciplina TCC2, fizemos um levantamento por meio de questionário simples sobre os impactos acadêmicos e artísticos que a experiência pedagógica interdisciplinar e a ação de extensão tiveram na formação dos estudantes que participaram deste processo. Os estudantes reconheceram de forma positiva a proposição de trabalharmos as três disciplinas conjuntamente com o intento de realizar uma exposição das pesquisas em arte dos formandos na Galeria da FAV. Recebemos também uma série de sugestões para melhorarmos a comunicação entre as disciplinas de forma que elas, juntas, estabeleçam contribuam para a finalização do TCC em harmonia com a finalização dos trabalhos artísticos e a montagem da exposição.

Um dos estudantes entrevistados afirmou que,

A proposta de unir as matérias de Expografia, Laboratório de Produção e TCC2 foi interessante para pensar nosso trabalho além da pesquisa teórica, como ele se desdobra ao entrar na Galeria, ao discutir montagem, curadoria, organização da exposição (ALUNO 01, 14 dez. 2017).

Outra aluna apontou para a importância da disciplina Expografia, que se mostrou como: 
[...] uma matéria bastante útil se pensarmos no contexto de uma produção de exposição dos trabalhos de TCC, é importante ter essa matéria para pensarmos a exposição de nosso próprio trabalho em uma exposição que realmente ficará de pé (ALUNA 02, 14 dez. 2017).

Uma terceira aluna reconheceu que:

[...] unir as três disciplinas foi uma experiência importante e pioneira na FAV que está mudando as estruturas antigas. Se isso for levado nos próximos anos acho que todos só têm a ganhar. Os alunos com a experiência expositiva em um espaço bom, desenvolvendo o TCC na teoria acompanhada pela produção prática, os "três pilares" se integram e resultam em processos e resultados mais completos (ALUNA 03, $14 \mathrm{dez} .2017$ ).

No que diz respeito à experiência dos alunos como mediadores do próprio trabalho na Galeria da FAV, um dos alunos apontou que:

[...]fui um dos monitores da exposição na galeria onde tive contato com os expectadores enquanto artista também e esse diálogo foi muito bom. Conversar com os transeuntes com a propriedade de um criador da obra é muito positivo pois pode ser dito mais sobre a poética e a execução da mesma (ALUNO 04, 14 dez. 2017).

\section{CONSIDERAÇÕES FINAIS}

Neste artigo, tratamos da produção prática e intelectual gerada a partir de uma ação pedagógica interdisciplinar que se desdobrou como ação de extensão universitária e que valorizou os eixos das artes visuais, cultura e educação. Destacamos o impacto que esta ação teve não só na formação acadêmica de nossos estudantes de graduação que participaram da proposta, mas também reconhecemos que ela reverberou positivamente em nós professoras e na comunidade em geral. A partir da interação das professoras com os estudantes envolvidos, a ação ganhou corpo, podendo ser concretizada de forma a atingir outros grupos, para além da universidade. No presente trabalho, concluímos que ao propormos um projeto interdisciplinar para conectar a sala de aula a uma experiência expositiva discente na Galeria da FAV, criamos um importante espaço de convergência entre ensino, pesquisa, extensão e formação profissional que beneficia estudantes, comunidade acadêmica e comunidade externa à UFG.

A exposição estabeleceu relações importantes entre a sala de aula, a pesquisa acadêmica e a apresentação pública dos trabalhos artísticos dos estudantes. 
O que se vê, então, nesta exposição, são produtos da longa caminhada acadêmica e artística estabelecida pelos estudantes do curso AVB. Tal produção entra em diálogo com o público à medida que são dispostos no espaço expositivo e a exposição de arte assume, assim, diversos papéis: de formação dos estudantes, ampliação das possibilidades pedagógicas dos professores, expansão do conhecimento dos visitantes da mostra por meio do contato direto com a pesquisa e com os próprios criadores dos trabalhos artísticos expostos.

É importante destacar que esta ação de extensão se justifica no momento em que constatamos que muitas pessoas que vivem próximo ao Campus II da UFG não costumam ir ou nunca estiveram numa exposição de artes visuais. Sendo assim, possibilitar que a comunidade em geral tenha acesso à Galeria da FAV, à pesquisa artística desenvolvida por nossos alunos, bem como estar em contato com os próprios estudantes no espaço expositivo faz com estendamos nossas ações e possamos contribuir para a formação de público em artes visuais. A exposição torna-se, assim, necessária não só à comunidade de estudantes da FAV/UFG, mas também à comunidade externa que passa a ganhar um lugar para refletir e conversar sobre o papel transformador da arte numa sociedade em constantes tensões. O conhecimento adquirido no fazer artístico e pelo contato direto com a arte é por si só propositivo e revolucionário, pois demanda que nos coloquemos constantemente em estados diferenciados no que diz respeito aos nossos modos de fazer, pensar, ver e compreender a nós mesmos e às realidades nas quais nos inserimos.

\section{REFERÊNCIAS}

AFONSO, Manoela dos Anjos; JORGE, Anahy Mendonça; SAMPAIO, Glayson Arcanjo de. Projeto pedagógico do curso Artes Visuais - Bacharelado. Goiânia: UFG, 2012.

CURY, Marília Xavier. Exposição: concepção, montagem e avaliação. São Paulo: Annablume, 2006, p.98 - 117 .

PAREYSON, Luigi, Os problemas da estética. São Paulo: Martins Fontes, 2001.

RANGEL, Sonia. O olho desarmado: objeto poético e trajeto criativo. Salvador: Solisluna Design Editora, 2009.

REY, Sandra. Da prática à teoria: três instâncias metodológicas sobre a pesquisa em poéticas visuais, v. 7, n. 13, Porto Alegre, nov. 1996, pp. 81-95.

SOGABE, Milton. [Carta] 17 set. 2014, Belo Horizonte [para] Senhor(a) Prof(a). Dr(a) Pró-Reitor(a) de Graduação, 2f. A importância da existência de espaços expositivos nos 
cursos de graduação em artes. Disponível em: <https://fcgartesvisuais.jimdo.com/app/ download/6102038351/Carta+aos+Pro\%CC\%81-Reitores+GALERIAS.pdf $>$ Acesso em: 20 fev. 2018.

SULLIVAN, Graeme. Art practice as research: inquiry in visual arts, $2^{\mathrm{a}}$ ed. London: Sage, 2010.

ZAMBONI, Silvio. Pesquisa em arte: um paralelo entre arte e ciência. $4^{\text {a }}$ ed. Campinas: Autores Associados, 2012. 